\title{
A MULTISENSOR APPROACH TOWARD A BETTER UNDERSTANDING OF SNOWFALL MICROPHYSICS The TOSCA Project
}

\author{
by U. Löhnert, S. Kneifel, A. Battaglia, M. Hagen, L. Hirsch, and S. Crewell
}

\section{Ground-based remote sensing and in situ measurements used in synergy help characterize the vertical distribution of snowfall necessary for satellite retrieval applications as well as for numerical model evaluation.}

AfFiliations: LöHnert, KNeifel, ANd CREWelL-Institute for Geophysics and Meteorology, University of Cologne, Cologne, Germany; BATTAGLIA-Department of Physics and Astronomy, University of Leicester, Leicester, United Kingdom; HAGENDeutsches Zentrum für Luft- und Raumfahrt, Institut für Physik der Atmosphäre, Oberpfaffenhofen, Germany; $\mathrm{HIRSCH}_{-}$MaxPlanck-Institute for Meteorology, Hamburg, Germany CORRESPONDING AUTHOR: Dr. Ulrich Löhnert, Institute for Geophysics and Meteorology, Zülpicher Straße 49a, 50674 Köln, Germany

E-mail: loehnert@meteo.uni-koeln.de

The abstract for this article can be found in this issue, following the table of contents.

DOI:10.1175/2010BAMS2909.1

In final form 6 December 2010

(C2011 American Meteorological Society concerning the rapid changes of the hydrological cycle in the polar regions. However, measuring snowfall is a highly complicated matter. The main challenges in adequately measuring snowfall are the high spatial and temporal variability as well as the enormous complexity of snow crystal habit, density, and particle size distribution (PSD).

Given the enormous uncertainties in the prediction of frozen hydrometeors in NWP and climate models, global and reliable monitoring of snow water content at middle and high latitudes is essential. Remote sensing methods are actually the only means suited for this purpose because they can provide continuous observations with high temporal coverage and spatially broad observations. Accurate surface-based in situ measurements of snowfall are only sporadically available around the globe; most operational stations only provide cumulative amounts of snowfall over the range of hours and even for these measurements many problems, such as wind-induced error, have been identified to be severe (Sevruk et al. 2009). Direct observations by airplanes can only deliver snapshots of extremely limited spatial and temporal extent. 
Numerous well-established remote sensing methods for deriving the liquid phase of precipitation from satellite sensors using passive microwave radiometry have been developed and are being routinely applied (e.g. Kummerow et al. 1996; Weng et al. 2003). A breakthrough for retrieving rainfall rates in the tropical regions was the launch of the Tropical Rainfall Measurement Mission (TRMM) satellite in 1997, which combines an active precipitation radar and passive microwave sensors (Iguchi et al. 2000). Remote sensing methods for deriving snowfall, in contrast, are much less sophisticated and suffer from large uncertainties. Recently, Noh et al. $(2006,2009)$ developed promising Bayesian approaches that relate radiances of the Advanced Microwave Sounding Unit B (AMSU-B) satellite sensors to ground-based snowfall rate, where the largest complications arise over snow-covered land and concerning the detection of light snowfall. CloudSat (Stephens et al. 2002), which was successfully launched in 2006, currently offers one of the most advanced possibilities for deriving the distribution of global snowfall (Liu 2008a). CloudSat is part of the international A-Train, a group of satellites flying in close formation so that the same scene can be observed by multiple satellites within seconds to minutes. The advantage of CloudSat's cloud profiling radar is that one can derive information on the vertical distribution of small cloud ice and snow particles and thus estimate the surface snowfall rate even during relatively light precipitation cases (Kulie and Bennartz 2009). However, such algorithms rely on empirical relations between the equivalent radar reflectivity factor $Z_{e}$ and snowfall rate, which are in turn a function of particle fall velocity and thus particle habit and PSD. It has been shown by Grecu and Olson (2008) that combing airborne cloud radar with high-frequency microwave channels above $89-220 \mathrm{GHz}$ can help constrain the snowfall rate retrieval from radar alone. In this sense, a drawback before the successful start of the CloudSat mission was the failure of the A-Train Aqua satellite Humidity Sounder for Brazil (HSB) instrument in February 2003, which was supposed to gather data at $150 \mathrm{GHz}$ and around the $183-\mathrm{GHz}$ water vapor absorption feature.

When regarding snowfall at temperatures below the freezing level, active cloud radar measurements are dominated by the backscatter signal originating from ice crystals, whereas passive microwave measurements are either insensitive to ice scattering (roughly below $50 \mathrm{GHz}$ ) or sensitive to both liquid water emission and ice particle scattering at frequencies above $90 \mathrm{GHz}$. Thus, when combining active and passive microwave measurements to improve snowfall retrievals, the correct quantification of the supercooled liquid water (SLW) phase is essential. This is interesting not only from the retrieval point of view but also from the microphysical science question concerning the role of SLW in snow production mechanisms such as diffusion (crystal growth via water vapor), riming (crystal growth due to freezing of SLW on existing crystals), and aggregation (crystal growth by the merging of two ice crystals). Large uncertainties still exist (Luo et al. 2008) concerning the consistent modeling of SLW, cloud ice water content (i.e., typically small pristine crystals), and snow water content (i.e., larger precipitating aggregate-like structures), partly because only very few sophisticated datasets for the intensive studying of mixed-phase clouds have become available (Verlinde et al. 2007). The latest modeling efforts show the necessity of available ground-based remote sensing, as well as in situ measurements, for improving mixed-phase cloud schemes of cloudresolving models (Solomon et al. 2009).

THE TOSCA PROJECT. In light of the abovementioned scientific challenges, the Towards an Optimal Estimation-based Snow Characterizing Algorithm (TOSCA) project, funded by the German Science Foundation (DFG), is currently being carried out. The intention of this paper is to give an overview of the goals of the TOSCA project, the applied instrumentation, and first results obtained from a measurement campaign in the winter of 2008/09.

The TOSCA focus is on the development of improved measurement techniques for snow and SLW at temperatures below freezing throughout the atmospheric column. At temperatures well below freezing, TOSCA concentrates on cases where melting processes do not play a role and thus the complex radiation signatures of melting snowflakes are not considered. The main TOSCA science questions are as follows:

- What are the combined influences of snow particle habit, PSD, mass density, and SLW on passive and active microwave observations?

- Do the TOSCA observations fit to results obtained from radiative transfer models assuming common snow crystal habits and size distributions?

- Can the accuracy of remote sensing retrievals of snow water be improved if active cloud radar measurements are combined with passive microwave measurements? 
To shed light on these questions, a unique combination of snowfall sensitive instruments has been deployed in a high Alpine environment at the Environmental Research Station Schneefernerhaus (UFS), Germany. The TOSCA instruments include two passive microwave radiometers (MWR), a cloud radar, a micro rain radar (MRR), a lidar ceilometer, two surface-based optical disdrometers, and standard meteorological observations.

In the following, we would like to introduce the readership to the unique TOSCA dataset and highlight the potential of these data toward consistent multi-instrument retrieval of snowfall and

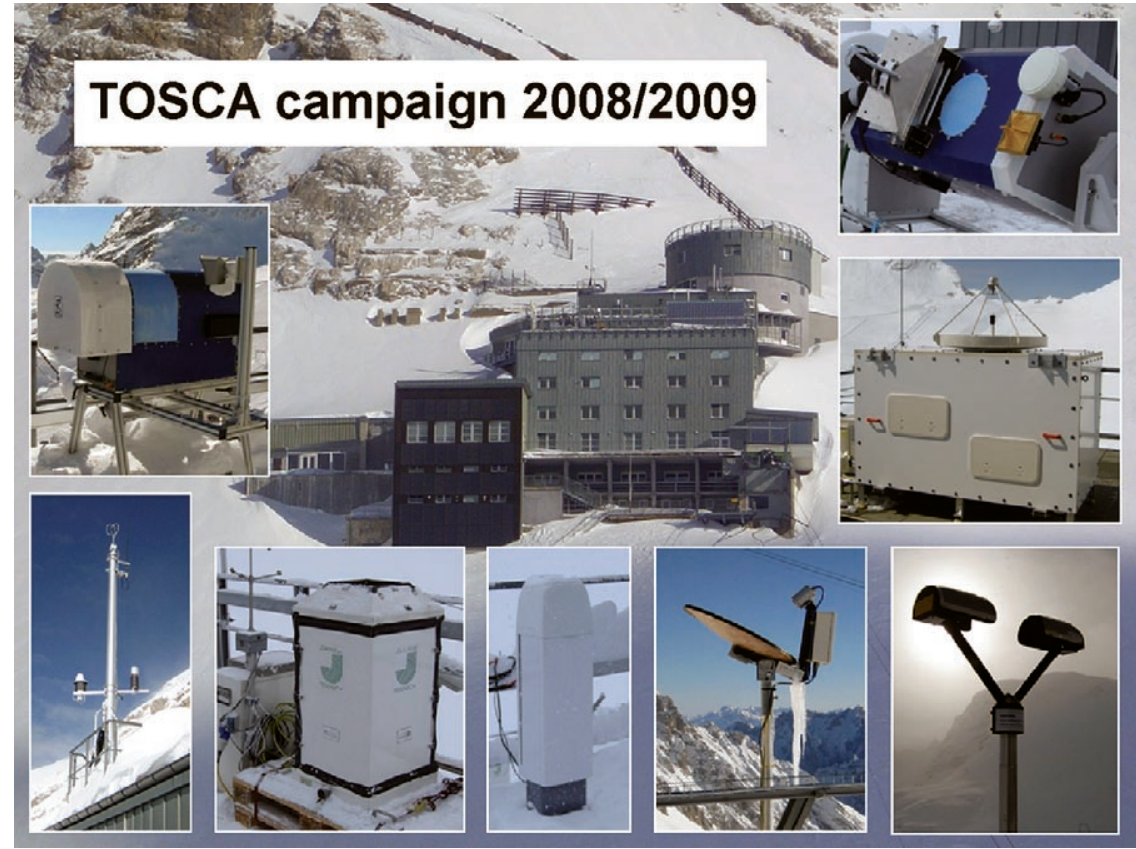

FIG. I. Impressions of instruments deployed at (middle) UFS located at the mountain of Zugspitze in the German Alps during the TOSCA measurement campaign in the winter season 2008/09: (middle left) microwave profiler HATPRO; (bottom left)-(bottom right) 10-m meteorological mast, 2DVD, ceilometer, MRR, Parsivel disdrometer; (middle right) 36-GHz cloud radar MIRA36; (top right) 90-/I50-GHz radiometer DPR. SLW. Thus, we commence

with a short overview of the location of the TOSCA 2008/09 winter campaign, instruments installed, and measurements carried out. Then, a first evaluation of combined measurements of microphysical snow properties will be shown on the basis of cloud radar, MWR, and a two-dimensional video distrometer (2DVD). Special emphasis is given to the MWR measurements because during the TOSCA campaign for the first time a longer time series of passive microwave measurements is evaluated toward their simultaneous sensitivity to SLW and snowfall. Finally, we would like to conclude with ideas for a future further exploitation of our data and how interested readers may gain access to the dataset.

UFS. The UFS is situated just $\sim 310 \mathrm{~m}$ below the peak of Germany's highest mountain (Zugspitze; $2969 \mathrm{~m}$ MSL) located at $47.42^{\circ} \mathrm{N}, 10.98^{\circ} \mathrm{E}$ (see Fig. 1). It was built and founded as a hotel in 1931 and is thus easily accessible via cable car. An outstanding feature, especially concerning the infrastructure for science applications, is the additional accessibility by a cog-wheel cable car, which was built through the Zugspitze and finished in 1930. It allows the installation of heavy equipment via a railway station within the mountain, located directly in a lower story of UFS. After the hotel closed down in 1992, it was transformed into an environmental research station in 1996 through a joint initiative of the Bavarian state and German federal government. One main focus lies in the observation of air quality: that is, UFS serves as a measurement and training center within the international Global Atmospheric Watch (GAW) program. It is also especially suited for "cold" snow $\left(<0^{\circ} \mathrm{C}\right)$ measurements because average temperatures are below $0^{\circ} \mathrm{C}$ in the months November-April. On average, 55\% of the total yearly precipitation $(1946 \mathrm{~mm})$ falls at surface temperatures below $0^{\circ} \mathrm{C}$. A further special advantage for the measurement of snow at microwave frequencies is the low amount of water vapor at the height of $2650 \mathrm{~m}$ MSL. The average column-integrated water vapor amount is below $4.8 \mathrm{~kg} \mathrm{~m}^{-2}$ (as opposed to $15.1 \mathrm{~kg} \mathrm{~m}^{-2}$ in Munich, which is located at a distance of about $100 \mathrm{~km}$ from the UFS at $\sim 580 \mathrm{~m} \mathrm{MSL}$ ), implying clearer, less attenuated scattering signals of snow in the passive microwave but also in the cloud radar measurements.

TOSCA INSTRUMENTATION. The technical specifications of the TOSCA instruments are shown in Table, 1 and the measurement potential of each instrument is also given in an overview in Table 2. 


\begin{tabular}{|c|c|c|c|}
\hline Instrument & Specification & Measurement quantity & Operation time \\
\hline HATPRO & $\begin{array}{l}\text { Passive remote sensing: } 14-\text { channel } \\
\text { microwave profiler at } 22-31 \mathrm{GHz} \text { and } \\
5 \mathrm{I}-58 \mathrm{GHz}\end{array}$ & Brightness temperature TB & $\begin{array}{l}\text { 2005-20 Feb 2009; } \\
22 \text { Dec 2009-present }\end{array}$ \\
\hline DPR & $\begin{array}{l}\text { Passive remote sensing: Two-channel } \\
\text { microwave radiometer at } 90 \text { and } \\
150 \mathrm{GHz} ; \mathrm{H} / \mathrm{V} \text { polarizations at } 150 \\
\mathrm{GHz}\end{array}$ & TB & $\begin{array}{l}\text { 2006-20 Feb 2009; } \\
22 \text { Dec 2009-present }\end{array}$ \\
\hline MIRA36 & $\begin{array}{l}\text { Active remote sensing (height } \\
\text { resolving): Polarimetric and Doppler } \\
\text { capable } 36-\mathrm{GHz} \text { cloud radar }\end{array}$ & $\begin{array}{l}\text { Radar reflectivity } Z_{\mathrm{e}} \text {; Doppler } \\
\text { velocity } v_{\mathrm{d}} \text {; LDR }\end{array}$ & 17 Oct 2008-4 May 2009 \\
\hline MRR & $\begin{array}{l}\text { Active remote sensing (height } \\
\text { resolving): Doppler capable MRR at } \\
24 \mathrm{GHz}\end{array}$ & $\begin{array}{l}\text { Doppler spectrum } \rightarrow \text { drop size } \\
\text { distribution; radar reflectivity }\end{array}$ & 24 Jan 2008-present \\
\hline Ceilometer & $\begin{array}{l}\text { Active remote sensing: Cloud base } \\
\text { detection via light pulses }\end{array}$ & Backscatter profile at $905 \mathrm{~nm}$ & 19 Aug 2008-20 Apr 2009 \\
\hline 2DVD & $\begin{array}{l}\text { In situ (surface level): 2D images of } \\
\text { snowflakes falling through measure- } \\
\text { ment volume; resolution of } 0.2 \mathrm{~mm}\end{array}$ & PSD; particle shape & 20 Jan-20 Mar 2009 \\
\hline Parsivel disdrometer & $\begin{array}{l}\text { In situ (surface level): ID images of } \\
\text { snowflakes falling through light sheet } \\
\text { maintained by diodes }\end{array}$ & $\begin{array}{l}\text { Fall velocity; max particle } \\
\text { diameter }\end{array}$ & 24 Jan 2008-4 May 2009 \\
\hline Web camera & Instrument surveillance & $\begin{array}{l}\text { Weather and precipitation } \\
\text { conditions }\end{array}$ & continuous \\
\hline $\begin{array}{l}\text { Standard meteorological } \\
\text { data (DWD) }\end{array}$ & $\begin{array}{l}\text { Temperature; humidity; wind; snow } \\
\text { accumulation }\end{array}$ & & continuous \\
\hline
\end{tabular}

\section{TABLE 2. Deployed TOSCA instruments and sensitivities of their measurements.}

\begin{tabular}{|l|l|l|l|}
\hline Instrument & \multicolumn{1}{|c|}{ Snowfall sensitivity } & \multicolumn{1}{c|}{ Cloud sensitivity } & \multicolumn{1}{c|}{ Other sensitivity } \\
\hline HATPRO & $\begin{array}{l}\text { Negligible: On the order of } \\
\text { calibration uncertainty }\end{array}$ & $\begin{array}{l}\text { Significant emission from bulk } \\
\text { liquid water; no sensitivity to } \\
\text { small ice particles }\end{array}$ & $\begin{array}{l}\text { Temperature profile ( 4 independent } \\
\text { layers); humidity profile (<2 indepen- } \\
\text { dent layers) }\end{array}$ \\
\hline MIRA36 & $\begin{array}{l}\text { TB enhancement during snowfall; } \\
\text { PSD and particle shape dependent; } \\
\text { orientation sensitive }\end{array}$ & $\begin{array}{l}\text { Strong emission from bulk liquid } \\
\text { water; no sensitivity to small ice } \\
\text { particles }\end{array}$ & Integrated water vapor content \\
\hline MRR & $\begin{array}{l}\text { Strong signal in reflectivity (PSD } \\
\text { and particle shape dependent); } \\
\text { fall velocity and vertical wind }\end{array}$ & $\begin{array}{l}\text { Moderate backscatter from } \\
\text { liquid clouds, significant from ice } \\
\text { clouds; linear depolarization from } \\
\text { orientated ice particles }\end{array}$ & Water vapor attenuation low at high \\
alpine site
\end{tabular}


Four of these instruments-the ones whose data are analyzed in this contribution-are highlighted in the following section.

In total, $1218 \mathrm{~h}$ of snowfall were captured with the available instruments from October 2008 to February 2009 (Table 3). Snowfall detection was achieved by combing the measurements of the 2DVD and the lowest bins of the cloud radar, and by means of the Web surveillance cameras of the MWR.

Of the available instruments, the cloud radar captured the great majority of the detected snowfall events, namely $92 \%$. The microwave radiometers show a much smaller fraction of snowfall time coverage, which was mainly due to a technical failure that led to a measurement failure of both systems on 20 February 2009. Additionally, reliable MWR measurements and 2DVD availability were given only from mid-January onward. In spite of the mentioned problems, the four main TOSCA instruments that are dealt with in this overview together captured a total of $132 \mathrm{~h}$ of snowfall. Note that all remote sensors are pointing vertically in the data analyzed below.

Passive microwave radiometer HATPRO. The microwave Humidity and Temperature Profiler (HATPRO) was designed by Radiometer Physics GmbH (RPG), Germany, as a network-suitable low-cost microwave radiometer that can observe liquid water path (LWP), humidity, and temperature profiles with high temporal resolution up to $1 \mathrm{~s}$ (Rose et al. 2005). HATPRO belongs to the UFS and measures atmospheric radiation within two bands in the microwave spectrum (Fig. 2).

The seven channels of the 22.235-31.4-GHz band contain information about the vertical profile of humidity through the pressure broadening of the optically thin 22.235- $\mathrm{GHz} \mathrm{H}_{2} \mathrm{O}$ line. By utilizing measurements around this absorption line, the determination of the vertically integrated water vapor content (IWV) is especially accurate $\left(\sim 0.5-0.8 \mathrm{~kg} \mathrm{~m}^{-2}\right)$. This band also contains information for determining the LWP through simultaneous measurements in the 31.4-GHz window channel and the water vapor sensitive channels around the water vapor line (Löhnert and Crewell 2003). Expected accuracies are on the order of 20-30 $\mathrm{g} \mathrm{m}^{-2}$. However, it must be mentioned at this point that the uncertainties in SLW absorption at these frequencies may be large because of missing

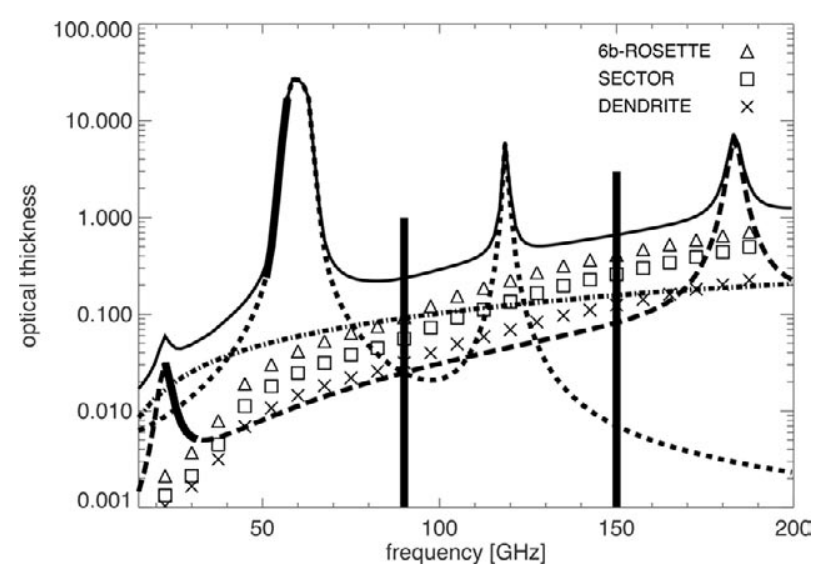

FIG. 2. Microwave spectrum: total optical thickness (bold) as a function of frequency calculated for a winter condition at UFS (surface temperature $\sim 270 \mathrm{~K}$ and IWV $\sim \mathrm{kg} \mathrm{m}^{-2}$ ). The assumed LWP is $0.1 \mathrm{~kg} \mathrm{~m}^{-2}$, whereas the SWP is set to $0.3 \mathrm{~kg} \mathrm{~m}^{-2}$. An exponential size distribution for the snowflakes is assumed (see text). The dotted line shows the contribution due to oxygen, the dashed line shows the contribution due to water vapor, and the dotted-dashed line shows the contribution due to liquid water. The different symbols indicate the resulting optical thickness due to the snow, assuming different snow particles according to Liu (2008b). The thick black lines show the measurement range of the microwave radiometers.

laboratory measurements at microwave frequencies higher than $10 \mathrm{GHz}$ (Mäztler and Morland 2009). This may lead to bias errors, which are difficult to quantify.

The seven channels of the $51-58-\mathrm{GHz}$ band contain information on the vertical profile of temperature due to the homogeneous mixing of $\mathrm{O}_{2}$ throughout the atmosphere (Crewell and Löhnert 
2007). At the opaque center of the $\mathrm{O}_{2}$ absorption complex at $60 \mathrm{GHz}$, most of the information originates from near the surface, whereas farther away from the line the atmosphere becomes less and less opaque so that more and more information also originates from higher atmospheric layers.

DPR. The Dual Polarization Radiometer (DPR) is a three-channel radiometer that belongs to the Ludwig Maximilian University of Munich and was specifically designed for the operation at UFS. It operates at 90 and $150 \mathrm{GHz}$, whereby a wire grid is used to separate the polarizations at the latter frequency so that both the vertical and horizontal polarizations can be measured separately and simultaneously.

The two channels are located in the window regions to the left and right of the $118-\mathrm{GHz} \mathrm{O}_{2}$ absorption line (Fig. 2). Because of the increasing sensitivity of liquid water absorption with frequency, the 90 - and $150-\mathrm{GHz}$ channels are $\sim 5$ and $\sim 7$ times more sensitive to liquid water, respectively, than the $31.4-\mathrm{GHz}$ window channel at UFS, such that DPR is ideally suited for detecting even low amounts of liquid water at the UFS location. Additionally, DPR is sensitive to snowfall, especially in the $150-\mathrm{GHz}$ channel (Fig. 2). Here, the snow crystals scatter back significantly the emission from the surface to yield a brightness temperature (TB) enhancement (Fig. 3). This effect is discussed in the later section on ground-based microwave signals during snowfall.

Because of advanced heated blower systems and (illuminated) Web camera surveillance, we can

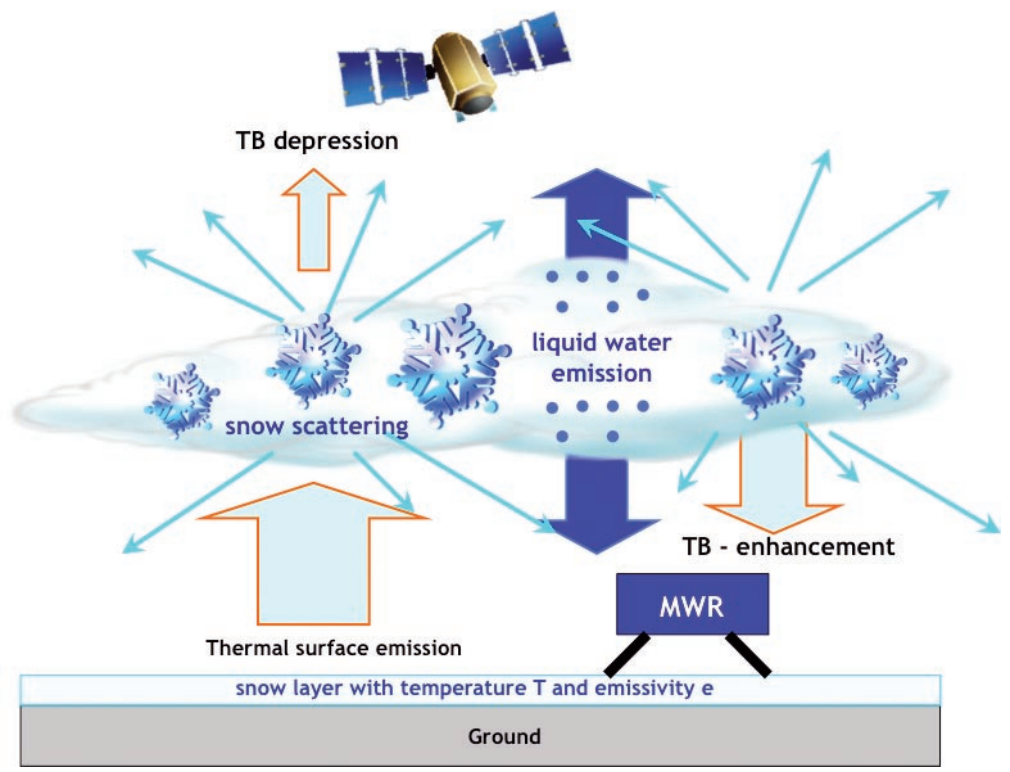

FIG. 3. Illustration of the effects of liquid water and snow crystals on microwave TB measured at surface level and from space. be sure that the measurements of both DPR and HATPRO are not obscured by liquid or frozen precipitation on the measurement windows.

Cloud radar MIRA36. MIRA36, designed by METEK $\mathrm{GmbH}$, Germany, is a $360-\mathrm{GHz}$ pulsed cloud radar designed for unattended long-term operation providing real-time continuous measurements of profiles of two linear polarizations of the radar reflectivity factor $Z_{e}$, the vertical Doppler velocity $v_{D}$, the velocity variance $\sigma_{D}$, linear depolarization ratio (LDR), and the Doppler spectra (Melchionna et al. 2008). Under standard operations, the minimum detectable reflectivity factor is $-44 \mathrm{dBZ}$ at a range of $5 \mathrm{~km}$. Thus, next to larger precipitation particles, it is also sensitive also to smaller, nonprecipitating cloud droplets and particles. The lowest range gate is limited to $300 \mathrm{~m}$ because of near-field effects, whereas significant signal to noise ratios can be detected up to $15-\mathrm{km}$ height. At UFS, the complete MIRA36 system was installed in a compact thermally stabilized container to ensure optimal performance during strong snowfall (see Fig. 1).

In a first quantitative way, MIRA36 measurements are very useful in identifying the vertical position of the precipitating and nonprecipitating hydrometeors. However, the quantitative derivation of mass content profiles is complicated because $Z_{e}$ is generally related to higher moments of the PSD: for example, to the sixth moment in case of liquid hydrometeors and approximately to the fourth moment in case of snowfall (Huang et al. 2010). Additional uncertainties arise because of resonant scattering effects and unknown particle densities.

Many attempts have been made to derive the ice or liquid water content from radar reflectivity measurements via power-law relationships (e.g. Hogan et al. 2006; Löhnert et al. 2008). However, such relationships may be subject to errors of $50 \%$ and more because of their dependency on PSD and particle shape.

Two-dimensional video disdrometer 2DVD. The 2DVD (Kruger and Krajewski 2002) was manufactured by Joanneum Research at the Institute of Applied Systems Technology in Graz, Austria. This in situ instrument provides information on size, shape, and fall velocity of precipitation particles. Raindrops, graupel, or snowflakes fall through two 
orthogonal light sheets, which are vertically separated by $6 \mathrm{~mm}$ to measure true fall speeds. The particles' shadows are recorded with two orthogonal line scan camera systems, whereby the effective measurement area is $10 \mathrm{~cm} \times 10 \mathrm{~cm}$, allowing even very large snowflakes to be sampled. The minimum detectable particle size is defined by the optical resolution of the camera system of $0.2 \mathrm{~mm}$.

Nešpor et al. (2000) have shown that large horizontal wind velocities can be responsible for potentially undersampling smaller particles, which is why the 2DVD is recommended to be operated with a surrounding wind fence of up to $6 \mathrm{~m}$ in diameter. However, the measurement environment at UFS did not offer the potential for installing a wind fence during the TOSCA campaign. To exclude possible disturbance by wind effects, only 2DVD measurements in low wind speed conditions $\left(v<5 \mathrm{~m} \mathrm{~s}^{-1}\right)$ were considered in the following analyses.

In this study, an exponential PSD is assumed for snow,

$$
N\left(D_{\max }\right)=N_{0} \times \exp \left(-\lambda D_{\max }\right),
$$

where $N\left(D_{\max }\right)\left(\mathrm{m}^{-4}\right)$ is the particle number density for a given maximum particle diameter $D_{\max }, N_{0}\left(\mathrm{~m}^{-4}\right)$ is the intercept parameter, and $\lambda\left(\mathrm{m}^{-1}\right)$ is the slope term. The PSD was calculated for a time interval of $10 \mathrm{~min}$, however, only if 300 or more snow particles were observed, to guarantee a sufficiently large sample size. The 2DVD software also provides an approximated particle volume (e.g., Brandes et al. 2007), which together with a density- $D_{\max }$ relation (Muramoto et al. 1995) yields the liquid equivalent snowfall rate. Because the particle volume approximation is based on only two projections, it cannot fully account for the full 3D structure of the snow crystals, and hence the derived snowfall rate should be interpreted with care.

Further instruments and measurements. In complementation to the above-described key instrumentation the TOSCA instrument suite also included two Vaisala ceilometers CT25K and CL31 for measuring the backscatter profile at 905 and $910 \mathrm{~nm}$, respectively, with a temporal resolution of $15 \mathrm{~s}$ and a vertical grid of $30 \mathrm{~m}$. During $80 \%$ of the snowfall cases, the lowest cloud base detection was below the lowest radar bin, indicating the frequent presence of SLW in this height range.

A micro rain radar was a second radar system that operated during TOSCA. It consists of a low-power $(50 \mathrm{~mW})$ Doppler radar $(24.1 \mathrm{GHz})$ operating in frequency-modulated continuous wave mode. From the measured Doppler spectra, profiles of the rain particle size distribution and terminal fall velocity can be derived (Peters et al. 2002). Compared to the cloud radar, the MRR sensitivity is rather low $(-5 \mathrm{dBZ}$ maximum in the lowest bin at $300 \mathrm{~m}$ ); however, it is very robust and practically no manpower is needed for the operation. Ongoing studies are currently evaluating the MRR system toward its potential for snowfall rate retrieval.

Furthermore, a Parsivel optical disdrometer (OTT $\mathrm{GmbH}, \mathrm{Germany)}$ was operated, which spans one light sheet with a surface of $27 \mathrm{~mm} \times 180 \mathrm{~mm}$ and a thickness of $1 \mathrm{~mm}$. It was originally designed for rain measurements but is also used to distinguish between different precipitation types such as graupel, hail, and snow (Löffler-Mang and Joss 2000). The degree of dimming due to the hydrometeors is measured by an optical detector array and is proportional to particle size. From this size estimation, the software algorithm derives the terminal fall velocity by assuming spherical hydrometeors, which, however, can lead to large uncertainties during snowfall (Battaglia et al. 2010).

\section{GROUND-BASED MICROWAVE SIGNALS} DURING SNOWFALL. In the following, we would like to introduce the reader to the effects of snow crystals and SLW droplets on ground-based MWR measurements. As explained in this section, SLW as well as snowfall leads to an increase in microwave TB, which is in contrast to observations from space.

Both from the ground-based and satellite perspective, cloud liquid water will lead to a temperature-dependent increase in TB due to thermal emission when viewed against a cold background (i.e., the cosmic background from the ground-based perspective and the ocean surface from space, respectively). However, for frequencies subject to scattering ( $>90 \mathrm{GHz}$ ), snowfall leads to a brightness temperature depression from the satellite point of view, whereas snowfall leads to a brightness temperature enhancement from the ground-based point of view (Fig. 3). The signal enhancement is caused by the microwave radiation emitted by the surface, which is exposed to scattering within the snow layer and, to a certain degree, is scattered back into the field of view of the radiometer. If a TB depression is observed from space, then we will also observe a TB enhancement from the ground. This is a result of the same scattering mechanisms; however, the finally observed TB will be a function of many other parameters such as surface emissivity, viewing angle, atmospheric opacity, etc. Kneifel et al. 
(2010) showed similar sensitivities to snow shape and PSD for both upward- and downward-looking geometries.

Simulations. The sensitivity of the employed MWR and cloud radar to snowfall in an Alpine environment has been modeled using the radiative transfer model RT3 (Evans and Stephens 1991), which assumes a horizontally stratified atmosphere. Although there is experimental evidence that larger single pristine dendrites even during snowfall are oriented preferably horizontally (Matrosov et al. 2005), the orientation of aggregate snow particles, which during TOSCA were observed to be often associated with significant snowfall, is not so distinct. In this simulation study, we have chosen randomly orientated dendrites, because these best represent the scattering signatures of realistic complex aggregates. To demonstrate the principal effects of snowfall on MWR measurements, we have used 2784 cases with snowfall from the operational mesoscale model Consortium for Small-Scale Modeling (COSMO-DE; online at www.cosmo-model.org/) of the German Weather Service (DWD) as input for RT3. Besides temperature, pressure, and humidity profiles, COSMO-DE prognostically calculates the specific contents of five hydrometeor classes: cloud liquid, cloud ice, liquid precipitation, snow precipitation, and graupel. Because the main focus of TOSCA is on nonmelting snowfall, only cases with surface temperatures $<-3^{\circ} \mathrm{C}$ have been included in the following sensitivity study. A temperature-dependent two-moment exponential PSD was assumed following Field et al. (2005), which is currently and frequently used in state-of-the-art microphysical parameterization schemes.

The resulting TB simulations (Fig. 4) clearly show an increase of ground-based microwave radiometer measurements at 90 and $150 \mathrm{GHz}$ with increasing vertically integrated snow water content: snow water path (SWP). The signal is especially significant if only ice crystals are considered in the TB simulations. If SLW is additionally considered, the TB increase (Fig. 4) as a function of SWP is much more noisy but still obvious. It is also clearly demonstrated that the scattering signal due to snowfall at $31 \mathrm{GHz}$ is very small (i.e., below $1 \mathrm{~K}$ in the range below $0.5 \mathrm{~kg} \mathrm{~m}^{-2}$ SWP). This implies that the liquid water retrievals carried out with the HATPRO channels from 22 to $31.4 \mathrm{GHz}$ will not be influenced by scattering due to snow crystals.

The SWP signal is also apparent in TB-TB scatterplots (Fig. 5). The larger SWP values at increasingly higher $150-\mathrm{GHz}$ TBs underline again the increased sensitivity toward SWP with respect to 31.4 and
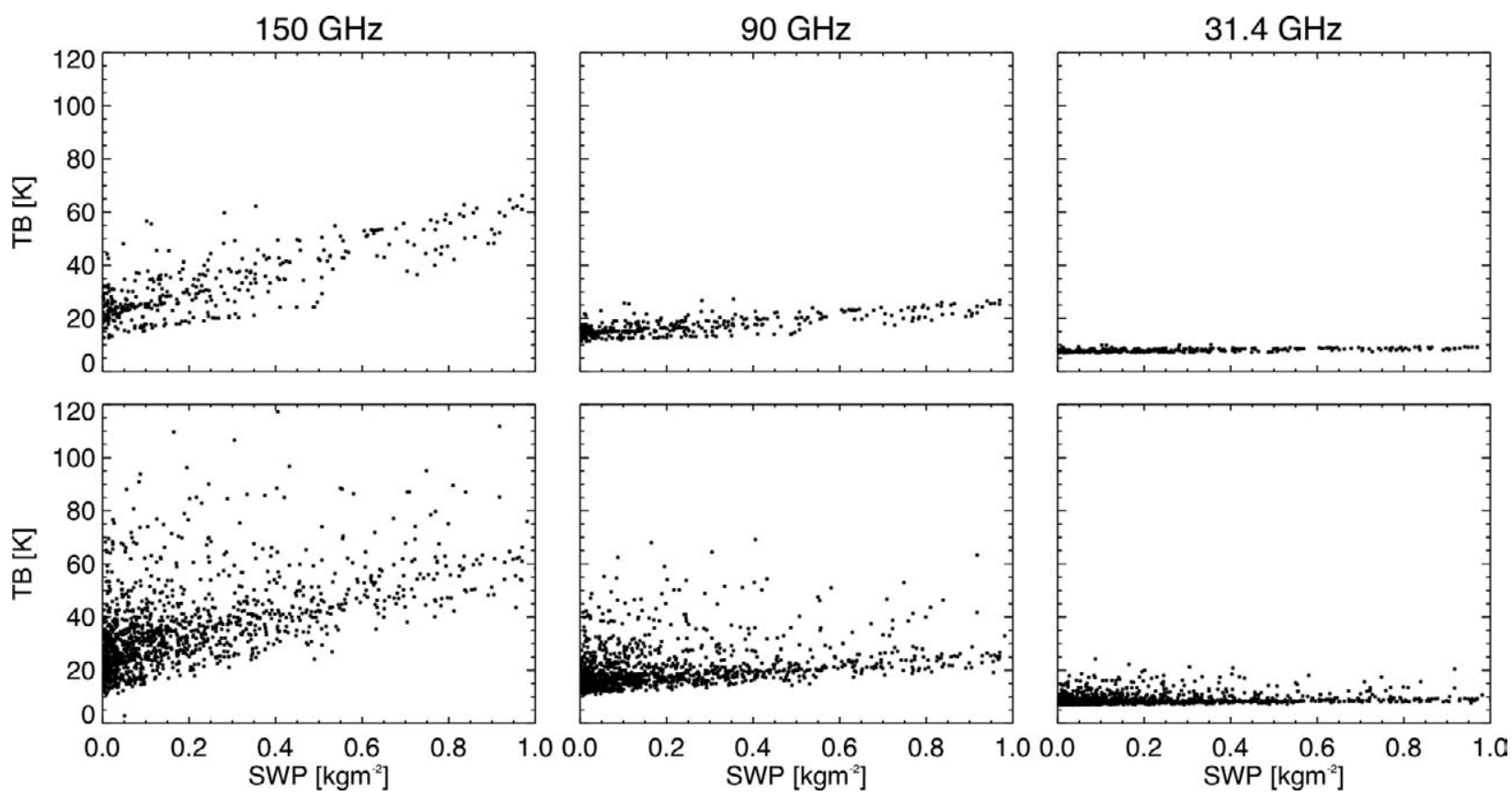

FIG. 4. Simulated sensitivity of TB at I50, 90, and $31 \mathrm{GHz}$ to SWP. A total of 2784 snowfall profiles corresponding best to the UFS location from the COSMO-DE model have been used for surface temperatures $<270 \mathrm{~K}$. The snow crystals are assumed to consist of dendrites (Liu 2008b). (top) Sensitivities for profiles containing only the hydrometeor species snow and cloud ice, and (bottom) sensitivities when the profiles additionally contain liquid water and graupel. The surface is assumed as a Lambertian reflector. 
$90 \mathrm{GHz}$. At $150 \mathrm{GHz}$, the snow scattering signal is largest, whereas at $31.4 \mathrm{GHz}$ the variance of the signal is almost solely caused by water vapor and liquid water variations. Figure 5 shows that modeled TB enhancements at $150 \mathrm{GHz}(90 \mathrm{GHz})$ range from a few Kelvin up to the order of about $50 \mathrm{~K}(15 \mathrm{~K})$. Although higher SWP are frequently observed with higher IWV (Fig. 5, middle), the bottom panels of Fig. 5 make the following clear: TB variations in the scatterplots due to IWV alone are much smaller compared to cases where significant amounts of SWP are present. All in all, the differential signals of multifrequency TB observations may prove valuable for distinguishing between IWV, SLW, and SWP.

However, it must be mentioned here that the magnitude of the SWP signal depends on different factors. (i) The surface snow emissivity can vary quite considerably. Generally, fresh snow will have a higher emissivity $(\sim 0.9)$ than older and more compact snow (0.6-0.7). Kneifel et al. (2010) have shown that varying the emissivity from 0.9 to 0.5 at an SWP value of $0.4 \mathrm{~kg} \mathrm{~m}^{-2}$ can have an effect of up to 10 and $5 \mathrm{~K}$ at 150 and $90 \mathrm{GHz}$, respectively. This means that specific care must be taken when interpreting snowfall measurements with varying surface emissivities: for example, at the beginning of snowfall events after a longer period without snowfall.

(ii) As can be seen in Fig. 2, the microwave optical thickness of snow varies considerably with crystal habit. This variation can result in TB differences of $10 \mathrm{~K}$ and more at $150 \mathrm{GHz}$. The database of
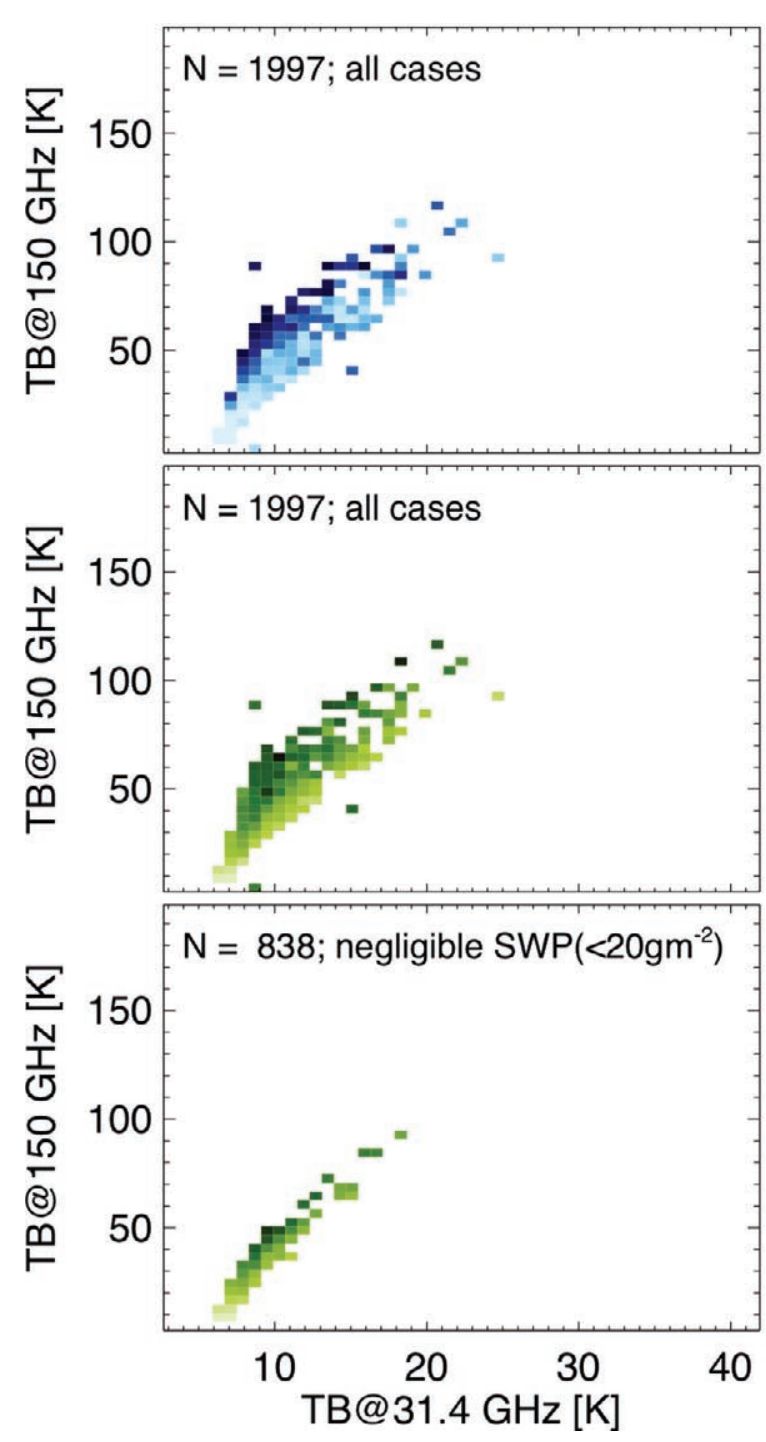

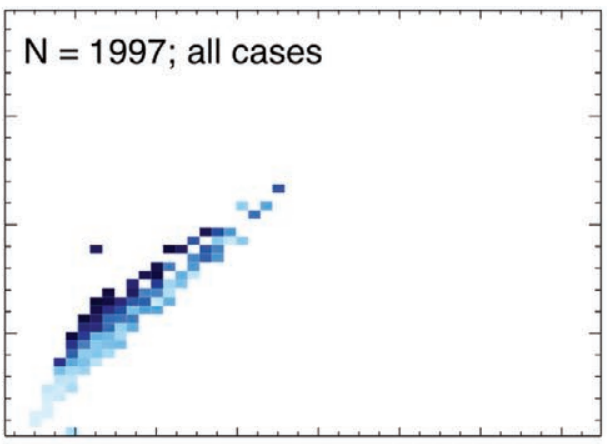

$\mathrm{N}=1997 ;$ all cases
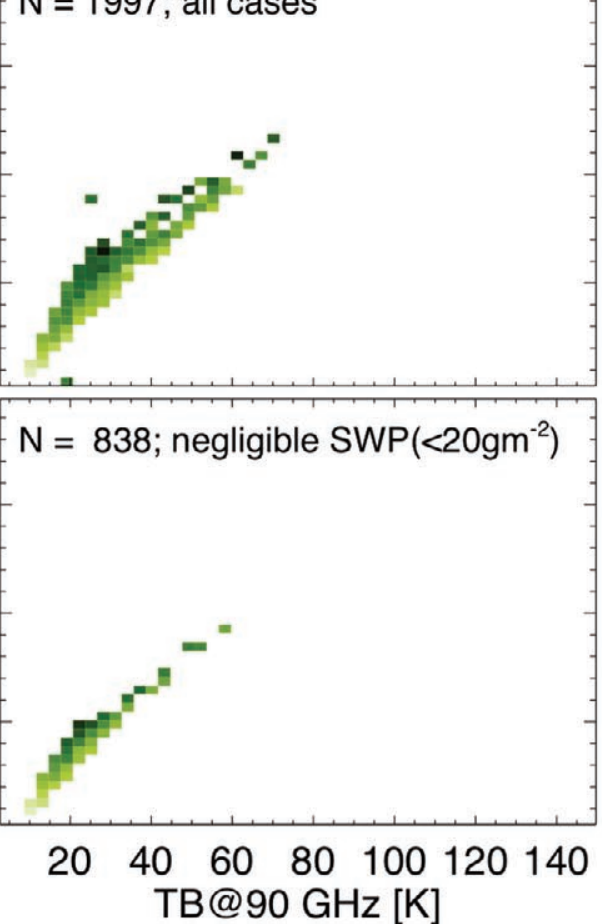

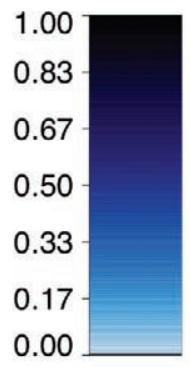

SWP $\left[\mathrm{kgm}^{-2}\right]$

FIG. 5. Simulated TB-TB scatterplots as a function of (top) SWP and (middle), (bottom) IWV: (left) 3I.4-GHz TB vs I50-GHz TB and (right) $90-$ GHz TB vs I50-GHz TB. In (bottom), only cases for SWP smaller than $20 \mathrm{~g} \mathrm{~m}^{-2}$ are shown. The analyzed data are the same as in Fig. 4. 
Liu (2008b) contains microwave scattering properties of 10 commonly assumed snow crystal habits, which allows the habit effects on TB to be studied in detail. However, the scattering properties of aggregates are still an open issue (Petty and Huang 2010) because of missing knowledge of both geometrical particle descriptions and their single scattering properties.

(iii) Correct descriptions of PSD are equally as important as particle shape (Kneifel et al. 2010). Because of gaps in knowledge and reasons of simplicity, many models and retrieval algorithms typically assume spheres with varying density and PSDs with a fixed intercept parameter and an exponential decrease toward larger particles. This implies that satellite retrieval algorithms for ice precipitation, which are frequently based on such assumptions, will be subject to bias error.

Measurements. The simulated TB enhancements have been observed during the TOSCA campaign (Fig. 6). The same TB-TB scatterplots as Fig. 5 are shown for real measurements and also show a clear dependence on the radar-derived SWP. Figure 6 shows that observed $\mathrm{TB}$ enhancements at $150 \mathrm{GHz}(90 \mathrm{GHz})$ range from a few Kelvin up to the order of about $70 \mathrm{~K}(30 \mathrm{~K})$, apart from a few outliers where TB enhancements can be even higher. When (as in Fig. 5) considering the scatterplots as a function of IWV and differentiating between all snowfall cases and cases with only negligible SWP amounts, we again see that the variability toward higher $90-/ 150-\mathrm{GHz}$ TBs is reduced when
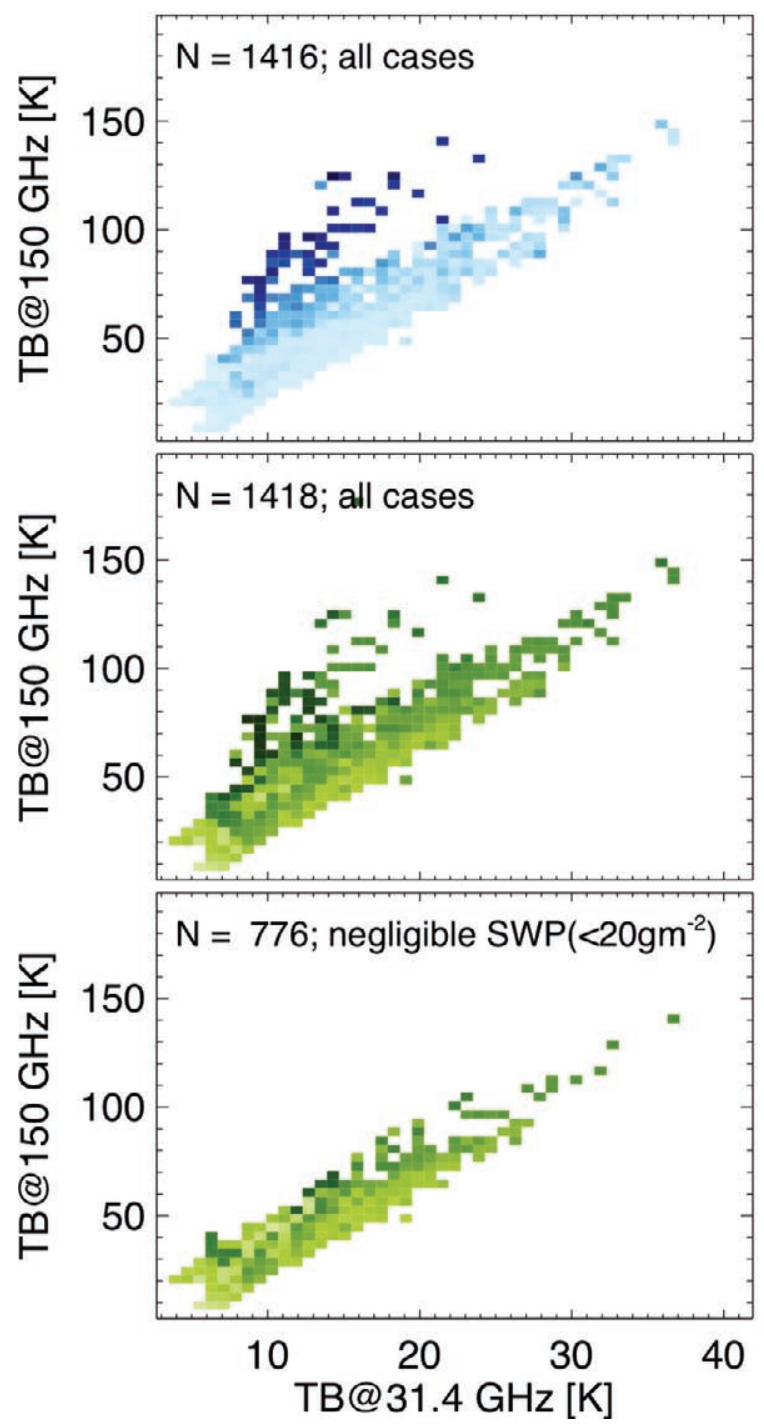
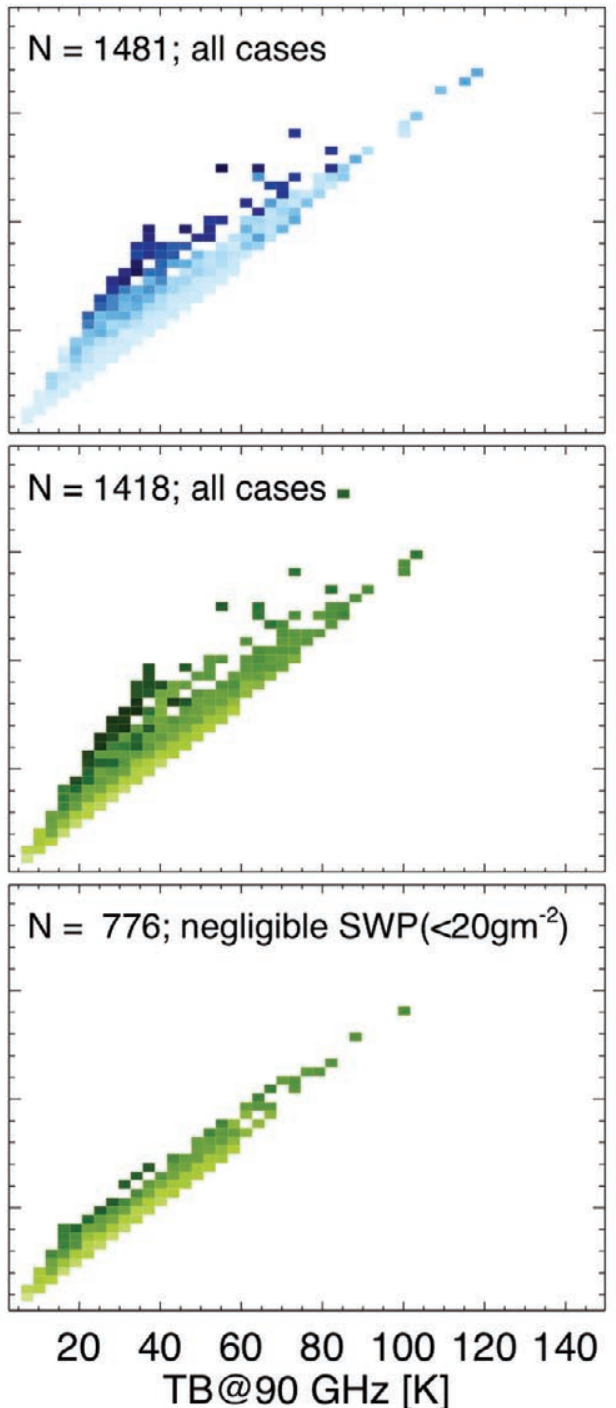

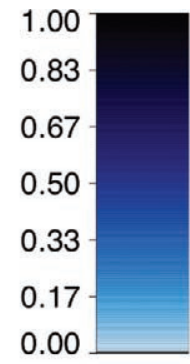

SWP $\left[\mathrm{kgm}^{-2}\right]$

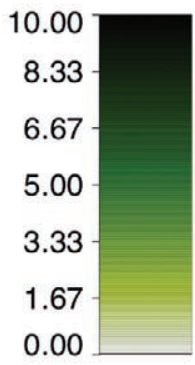

IWV $\left[\mathrm{kgm}^{-2}\right]$

FIG. 6. TB-TB scatterplots as a function of (top) SWP and (middle), (bottom) IWV: (left) 3I.4-GHz TB vs I50-GHz TB and (right) $90-\mathrm{GHz}$ TB vs I50-GHz TB. In (bottom), only cases for SWP smaller than $20 \mathrm{~g} \mathrm{~m}^{-2}$ are shown. 
no snowfall is present, although the IWV values are within the same range in both scenarios.

Evidently, the regions covered by simulations (Fig. 5) and observations (Fig. 6) are not the same, whereas larger scattering signals are present in the observations. These inconsistencies may arise from the assumptions in the TB simulations for crystal type and PSD. The PSDs calculated according to Field et al. from the COSMO output generally exhibit more smaller particles and less larger particles than the PSDs observed by the 2DVD at the surface, which would be consistent with the larger TB enhancements observed. This example makes clear how datasets such as TOSCA may help improve microphysical assumptions needed for retrieval algorithm development as well as microphysical parameterizations.

Note that, in contrast to the simulations, we still see a rather large range of scatter in the $150-\mathrm{GHz}$ versus 31.4-GHz plot in cases of negligible SWP. We attribute this variability mainly to the differences in temperature dependence of the emission of SLW at 31.4 and $150 \mathrm{GHz}$. At $31.4 \mathrm{GHz}$, the same amount of SLW gives rise to higher TBs at colder ambient temperature than at warmer temperature, whereas this relation is opposite at $150 \mathrm{GHz}$. Apparently, the temperature range in which SLW occurs in the model is much more restricted than in reality.

\section{FIRST TOSCA MEASUREMENT STATIS-}

TICS. Following the detailed interpretation of the TB signals during snowfall, a few preliminary relations between the derived parameters from the single instruments are discussed. Note that the temperatures mentioned in the discussion below refer to the surface temperature measured at UFS, which, to a certain extent, are assumed to be representative of the environment of the microphysical processes at stake because, during $80 \%$ of all snowfall events, UFS was located at maximum $280 \mathrm{~m}$ below cloud base (as determined by the ceilometer).

In situ: Temperature-dependent crystal sizes. The comprehensive 2DVD observations made by Brandes et al. (2007) show a sharp increase of particle size at temperatures above $-5^{\circ} \mathrm{C}$. They note that this "primary aggregation growth region" can most probably be explained by a quasi-liquid film on the surfaces of ice surfaces (Rosenberg 2005) leading to an increased "stickiness" (i.e., higher collection efficiency). It was not possible to observe this strong increase during the TOSCA because only a small part of the observations took place above $-5^{\circ} \mathrm{C}$.

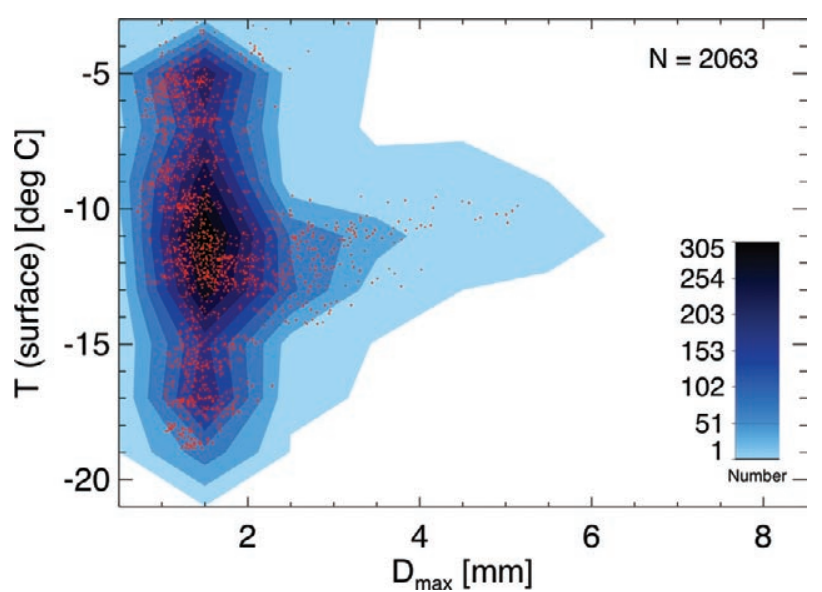

Fig. 7. Surface temperature as a function of snow crystal maximum diameter during TOSCA. The actual measurements points corresponding to 10 -min averages are shown in orange.

However, an interesting feature can still be observed from the evaluation of the histogram of maximum particle size dimension $D_{\text {max }}$ (obtained from the 2DVD) and surface temperature (Fig. 7). Maximum particle size dimension $D_{\text {max }}$ seems to be temperature independent with maximum occurrences around 1.0 to $1.5 \mathrm{~mm}$, except for the temperature range between $-10^{\circ}$ and $-15^{\circ} \mathrm{C}$, where we clearly see the more frequent occurrence of much larger snow crystals. In this temperature range, the supersaturation over ice with respect to liquid water reaches its maximum value so that the Wegener-Bergeron-Findeisen process (Korolev 2007) (i.e., the transformation of liquid drops to ice crystals via the gas phase) may be especially effective. Additionally, snow crystals are mostly of dendritic structure in this temperature range (Libbrecht 2005). Both conditions are preferable for the fast and effective growth of snow crystals in this "secondary growth region" of preferred aggregation growth, which has also been previously observed by Hobbs et al. (1974) and Hosler and Hallgren (1960). Note that, for example, the sticking efficiency of ice particles in state-of-the-art cloud models is often parameterized as simple function of temperature (e.g., Seifert and Beheng 2006).

Microwave LWP versus cloud radar SWP. Using the combined measurements of cloud radar and MWR, we have the exceptional possibility of measuring the SWP and LWP simultaneously and independently. The SWP histogram of a total of $469 \mathrm{~h}(2813$ of 10-min averages; Fig. 8) of snowfall shows that $\sim 60 \%$ of all snowfall events show SWP values in the range from 0 to $0.05 \mathrm{~kg} \mathrm{~m}^{-2}$, whereas the median of 
LWP in this SWP class is on the order $\left(\sim 0.1 \mathrm{~kg} \mathrm{~m}^{-2}\right)$. Additionally, we see that only $25 \%$ of all cases in this SWP class have an LWP lower than $0.04 \mathrm{~kg} \mathrm{~m}^{-2}$. Obviously, the sustainment of snowfall events with low amounts of SWP is correlated to the existence of SLW. Note that, even in $25 \%$ of the cases, LWP values are larger than $0.2 \mathrm{~kg} \mathrm{~m}^{-2}$. Further evaluation of Fig. 8 makes clear that the median LWP of all SWP classes from 0.1 to $0.4 \mathrm{~kg} \mathrm{~m}^{-2}$ is nearly constant within a range of $0.05-0.08 \mathrm{~kg} \mathrm{~m}^{-2}$, allowing the conclusion that in most snowfall cases liquid water plays a role in the snowfall process and that

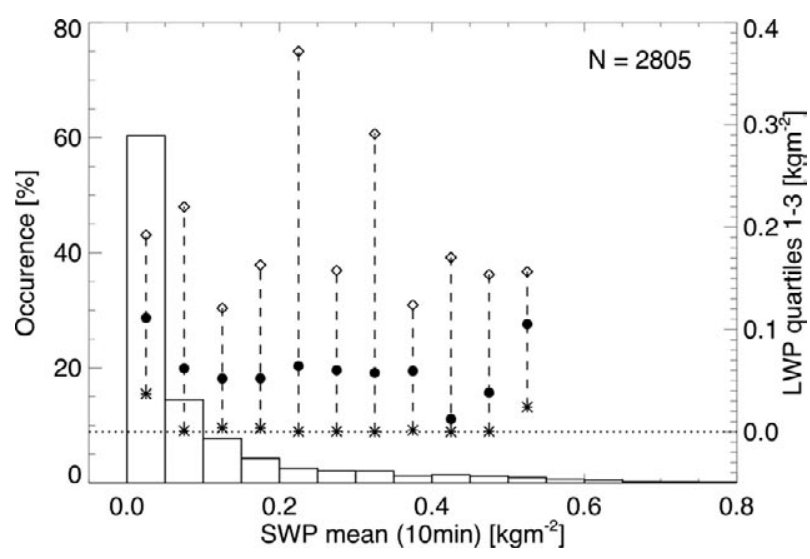

FIG. 8. SWP distribution and corresponding LWP quartiles I, 2, and 3 during snowfall events at UFS. Note that quartile I corresponds the $25 \%$ percentile (stars), quartile 2 corresponds to the median (bullets), and quartile 3 corresponds to the $75 \%$ percentile (diamonds). SWP and LWP are calculated according to the methods by Löhnert and Crewell (2003) and Hogan et al. (2006), respectively. the popularly called dry snow cases (i.e., snowfall without coexisting liquid phase) exist only in the minority of the cases at the UFS.

Most observed snowfall events ( 25\%) occur at surface temperatures between $-10^{\circ}$ and $-12^{\circ} \mathrm{C}$ (Fig. 9 , left). A tendency can be observed that larger SWP values occur more frequently at higher temperatures. In addition to the higher water vapor abundance, this may be related to the fact that snowfall events observed at higher temperatures were associated with significantly deeper cloud extensions than at colder temperature (Table 4). Deeper clouds may give rise to higher vertical velocities and thus result in more intensified crystal growth processes such as aggregation or riming.

In contrast to the observed increase of SWP with temperature, LWP values show a tendency to increase with decreasing temperature during the observed snowfall cases (Fig. 9, right). We also see that typical LWP values during the most frequently observed snowfall events are again on the order of $0.1 \mathrm{~kg} \mathrm{~m}^{-2}$. At temperatures below $-15^{\circ} \mathrm{C}$, SWP values are small and seldom exceed $0.1 \mathrm{~kg} \mathrm{~m}^{-2}$, though LWP values can be relatively large. At these temperatures, snow crystals are generally less "sticky"; at temperatures below $-20^{\circ} \mathrm{C}$, pristine crystal habits such as plates or columns are more likely to exist (Libbrecht 2005). Both conditions are not favorable for an effective aggregation process. Additionally, at temperatures below $-15^{\circ} \mathrm{C}$, the excess of water vapor saturation over ice water with respect to liquid water decreases again so that at lower temperatures the effectiveness of the Wegener-Bergeron-Findeisen process is more and more reduced.
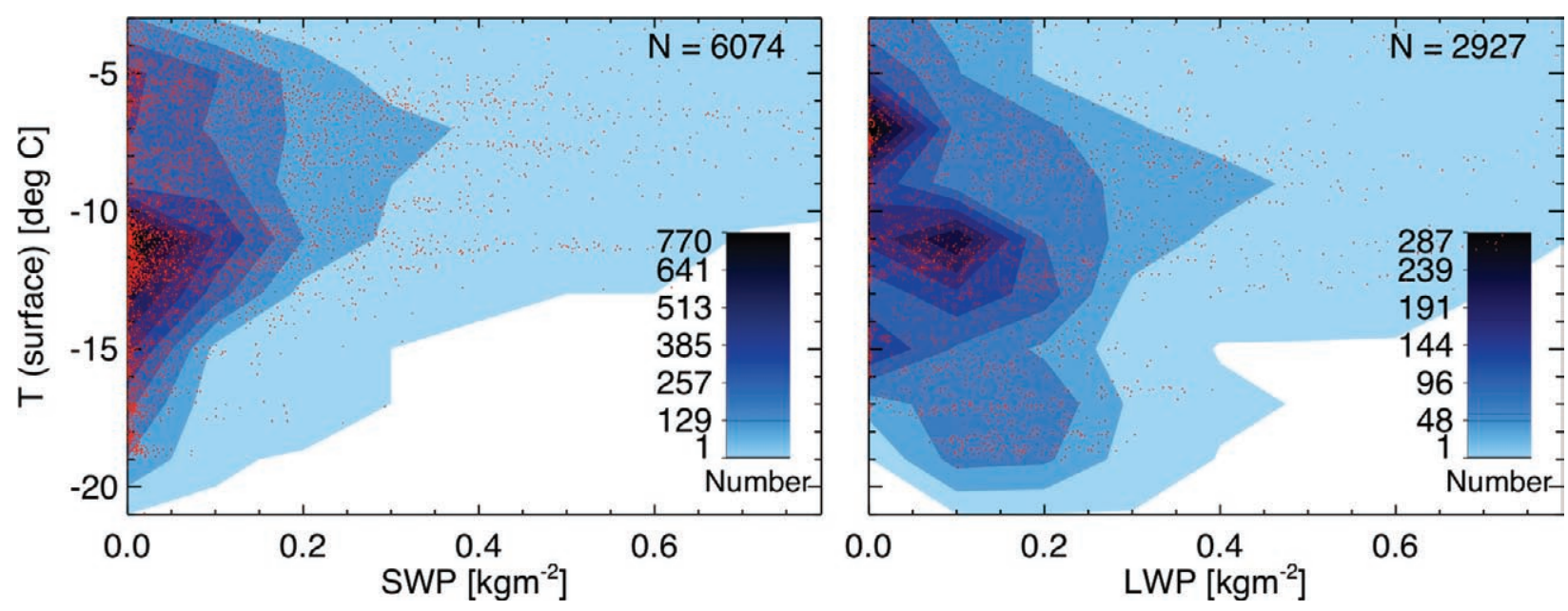

Fig. 9. Surface temperature contours as a function of (left) SWP and (right) LWP during TOSCA. The actual measurement points corresponding to 10 -min averages are shown in orange. 
In situ versus cloud radar. An important question when combing ground-based in situ measurements such as the 2DVD with the remote sensing measurements is to what extent the in situ measurements may be used to constrain remote sensing measurements within the atmospheric column.

We have examined the 10-min reflectivity averages of the three lowest radar bins ranging from 285 to $375 \mathrm{~m}$ above the UFS observatory (Fig. 10, left). Principally, the 2DVD-derived snowfall rate at the surface shows an increasing tendency with increasing reflectivity; however, the range of scatter is very high. This may be caused by the fall time delay (min) from $300 \mathrm{~m}$ to the surface; microphysical processes, which occur downward from $300 \mathrm{~m}$ above the site; horizontal advection; uncertainties in the 2DVD snowfall rate derivation (which requires accurate estimates of particle mass and fall velocity); and the inherent uncertainties between radar reflectivity and the snowfall rate.

Similar uncertainties will also be present when interpreting cloud radar reflectivity from spacebased cloud radar such as CloudSat, whose lowest interpretable range bin lies approximately $1 \mathrm{~km}$ above the surface. During $11 \%$ of all snowfall events, the measurements at $1 \mathrm{~km}$ missed a snowfall reflectivity signal where there was a detectable signal at $300 \mathrm{~m}$. Additionally, the snowfall rate is $30 \%$ lower on average at $1 \mathrm{~km}$ than at $300 \mathrm{~m}$ assuming a $Z_{e}$-snowfall rate relation according to Matrosov (2007).

It should be noted at this point that during TOSCA we practically observed no relationship be- tween SWP and the 2DVD-measured snowfall rate. Whereas the correlation of the average of the lowest three radar reflectivity bins and the snowfall rate is on the order of 0.4 , the correlation between SWP and snowfall rate is only $\sim 0.1$. This shows the difficulty in drawing conclusions from the vertically integrated snow water content to the ground-based snowfall intensity and with how much care data from passive satellite retrievals, which mostly sense information on columnar contents, need to be interpreted.

The right panel of Fig. 10 also nicely shows that the PSD exponential fit parameter $\lambda$ measured at the surface decreases with increasing radar reflectivity at 300 - $\mathrm{m}$ height. This means that higher $Z_{e}$ values give rise to broader PSDs with a higher number of larger crystal sizes. Although, as for the evaluation of the snowfall rate, the degree of scatter is very large, these examples show that ground-based 2DVD measurements have the potential of adding independent pieces of information to retrievals of snow microphysical properties from cloud radar.

SUMMARY AND OUTLOOK. With the TOSCA dataset, we have presented an unprecedented combination of measurements that can provide key ad-
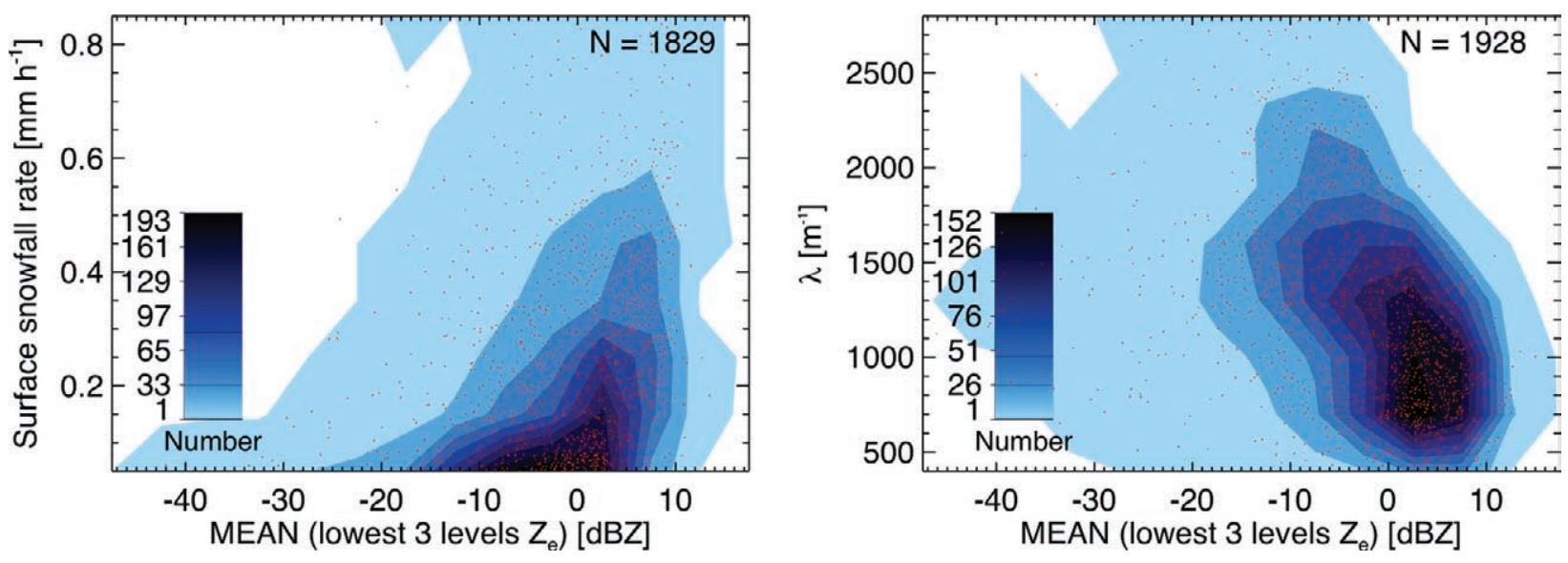

FIG. 10. (left) 2DVD-derived snowfall rate and (right) lambda slope parameter as a function of the average of the lowest 3 levels of radar reflectivity during TOSCA. The actual measurements points corresponding to $10-\mathrm{min}$ averages are shown in orange. 
ditional pieces of information needed to improve the understanding of the microphysical characteristics of midlatitude winterly precipitation systems. It must of course be clearly stated that the measurements shown here are only representative for a limited number of weeks during the season of 2008/09 and that they are also dominated by the surrounding orographic terrain. Independent measurements of similar constitution at different sites are necessary.

In a first data analysis, we have seen that groundbased MWR measurements at $90-$ and $150-\mathrm{GHz}$ measurements are sensitive not only to liquid water but also to column snow water content. However, to use these measurements in synergy with cloud radar, IWV, LWP, and surface emissivity must be well characterized. To finally determine if the combination of ground-based radar and MWR will lead to an improved SWP, an information content analysis of a statistically significant set of realistically modeled snowfall cases must be available, including realistic snow particle shapes and PSDs as well as surface emissivities and their corresponding variabilities, a study that this manuscript can only motivate. Additionally, we have shown the potential of the TOSCA dataset for deriving information on microphysical processes such as aggregation and diffusion growth. By simultaneously analyzing temperature and particle size measurements, we could provide support for the theory of the existence of a "secondary aggregation growth region" around $-12^{\circ}$ to $-15^{\circ} \mathrm{C}$. Our data also revealed the existence of significant amounts of SLW in more the $75 \%$ of all snow events, as well as a tendency of an LWP increase with decreasing temperature.

It is clear that vertical profiling of snow-bearing clouds will remain one of the greatest and intriguing challenges of Earth science in the upcoming years, which propels our effort toward a ground-validation approach of snow microphysical processes. We would like to emphasize that TOSCA-like measurements may in future constitute a test bed in particular for current and future satellite retrieval methodologies. As mentioned above, CloudSat does not acquire practically any information below $1000 \mathrm{~m}$ above the surface because of "surface contamination" of the signal. This region, however, is of high significance for the surface snowfall rates and can only be characterized by ground-based remote sensors as deployed in TOSCA in conjunction with surface in situ measurements. Thus, TOSCA measurements may contribute to describing the representativeness of CloudSat measurements for deriving ground-based snowfall rates. Additionally, by combining active and passive microwave remote sensing measurements at necessary multiple frequencies, essential assumptions on particle type and size distribution may be evaluated through consistency checks with radiative transfer modeling in snow clouds. These assumptions can further be constrained by the in situ measurements and continuous temperature and humidity profile information. Thus, such measurements can be of high importance for the development of new spaceborne algorithms. Also, the TOSCA data may provide potentially useful for evaluating cold cloud microphysical schemes in NWP and climate models in the frame of a model-to-measurement approach.

Measurements as carried out during TOSCA are vital from the perspective of space-borne missions under final preparation [Earth Clouds, Aerosols, and Radiation Explorer (EarthCARE); Kumagai et al. 2003] and envisaged for the near future (Tanelli et al. 2009), which is why a permanent installation of a cloud radar at the UFS in the near future is planned, additional to the permanent MWR (available again since December 2009) and ceilometer measurements currently carried out. Additionally, the future deployment of radars and radiometers with enhanced multifrequency and polarimetric capabilities will be valuable in retrieving particle shape as well as PSD information. The interested reader may find an overview and access to the collected data online (at http://gop.meteo.uni-koeln.de/tosca/) or by directly contacting the corresponding author.

ACKNOWLEDGMENTS. The authors would like to thank the team at the UFS under lead of Markus Neumann for supplying the advanced measurement infrastructure during the harsh weather conditions at UFS. We are grateful to Dr. Michael Schönhuber and Günther Lammer at Joanneum Research at the Institute of Applied Systems Technology in Graz, Austria, for providing the 2DVD instrument. Meinhard Seefeldner and Anton Lex (both of LMU Munich) and Radiometer Physics GmbH supported the operation of the microwave radiometers under extreme winter conditions. Additionally, Stephanie Redl (University of Cologne), Dr. Bernhard Pospichal (University of Natural Resources and Applied Life Sciences, Vienna), and Dominik Siebler (DLR, Oberpfaffenhofen) helped us significantly concerning instrument maintenance and data postprocessing. The COSMO-DE model output was provided through Axel Seifert of DWD in the frame of the German Research Foundation (DFG) Priority Program 1167. TOSCA is supported by the DFG under Research Grants LO 901/3-1, BA 3485/2-1, HA 3314/5-1, and PE $332 / 8-1$. 


\section{REFERENCES}

Battaglia, A., E. Rustemeier, A. Tokay, U. Blahak, and C. Simmer, 2010: PARSIVEL snow observations: A critical assessment. J. Atmos. Oceanic Technol., 27, 333-344.

Brandes, E. A., K. Ikeda, G. Zhand, M. Schönhuber, and R. M. Rasmussen, 2007: A statistical and physical description of hydrometeor distributions in Colorado snowstorms using a video disdrometer. J. Appl. Meteor. Climatol., 46, 634-650.

Crewell, S., and U. Löhnert, 2007: Accuracy of boundary layer temperature profiles retrieved with multifrequency multiangle microwave radiometry. IEEE Trans. Geosci. Remote Sens., 45, 2195-2201, doi:10.1109/TGRS.2006.888434.

Evans, K. F., and G. L. Stephens, 1991: A new polarized atmospheric radiative transfer model. J. Quant. Spectrosc. Radiat. Transfer, 46, 413-423.

Field, P. R., R. J. Hogan, P. R. A. Brown, A. J. Illingworth, T. W. Choularton, and R. J. Cotton, 2005: Parametrization of ice particle size distributions for mid-latitude stratiform 19 cloud. Quart. J. Roy. Meteor. Soc., 131, 1997-2017.

Grecu, M., and W. S. Olson, 2008: Precipitating snow retrievals from combined airborne cloud radar and millimeter-wave radiometer observations. J. Appl. Meteor. Climatol., 47, 1634-1650.

Hobbs, P. V., S. Chang, and J. D. Locatelli, 1974: the dimensions and aggregation of ice crystals in natural clouds. J. Geophys. Res., 79, 2199-2206.

Hogan, R. J., M. P. Mittermaier, and A. J. Illingworth, 2006: The retrieval of ice water 18 content from radar reflectivity factor and temperature and its use in the evaluation of a 19 mesoscale model. J. Appl. Meteor. Climatol., 45, 301-317.

Hosler, C. L., and R. E. Hallgren, 1960: The aggregation of small ice crystals. Discuss. Faraday Soc., 30, 200-207.

Huang, G.-J., V. N. Bringi, R. Cifelli, D. Hudak, and W. A. Petersen, 2010: A methodology to derive radar reflectivity-liquid equivalent snow rate relations using C-band radar and a 2D video disdrometer. $J$. Atmos. Oceanic Technol., 27, 637-651.

Iguchi, T., T. Kozu, R. Meneghini, J. Awaka, and K. Okamoto, 2000: Rain-profiling algorithm for the TRMM precipitation radar. J. Appl. Meteor., 39, 2038-2052.

Kneifel, S., U. Löhnert, A. Battaglia, S. Crewell, and D. Siebler, 2010: Snow scattering signals in ground-based passive microwave radiometer measurements. J. Geophys. Res., 115, D16214, doi:10.1029/2010JD013856.
Korolev, A., 2007: Limitations of the WegenerBergeron-Findeisen mechanism in the evolution of mixed-phase clouds. J. Atmos. Sci., 64, 3372-3375.

Kruger, A., and W. F. Krajewski, 2002: Two-dimensional video disdrometer: A description. J. Atmos. Oceanic. Technol., 19, 602-617.

Kulie, M. S., and R. Bennartz, 2009: Utilizing spaceborne radars to retrieve dry snowfall. J. Appl. Meteor. Climatol, 48, 2564-2580.

Kumagai, H., H. Kuroiwa, S. Kobayashi, and T. Orikasa, 2003: Cloud profiling radar for Earthcare mission. Microwave Remote Sensing of the Atmosphere and Environment III, C. D. Kummerow, J. Jiang, and S. Uratuka, Eds., International Society for Optical Engineering (SPIE Proceedings, Vol. 4894), 118-125.

Kummerow, C., W. S. Olson, and L. Giglio, 1996: A simplified scheme for obtaining precipitation and vertical hydrometeor profiles from passive microwave sensors. IEEE Trans. Geosci. Remote Sens., 34, 1213-1232.

Libbrecht, K. G., 2005: The physics of snow crystals. Rep. Prog. Phys., 68, 55-895.

Liu, G., 2008a: Deriving snow cloud characteristics from CloudSat observations. J. Geophys. Res., 113, D00A09, doi:10.1029/2007JD009766.

_, 2008 b: A database of microwave single-scattering properties for nonspherical ice particles. Bull. Amer. Meteor. Soc., 89, 1563-1570.

Löffler-Mang, M., and J. Joss, 2000: An optical disdrometer for measuring size and velocity of hydrometeors. J. Atmos. Ocean. Technol., 17, 130-139.

Löhnert, U., and S. Crewell, 2003: Accuraccy of cloud liquid water path from ground-based microwave radiometry 1. Dependency on cloud model statistics. Radio Sci. 38, 8041, doi:10.1029/2002RS002654.

,,-- O. Krasnov, E. O'Connor, and H. Russchenberg, 2008: Advances in continuously profiling the thermodynamic state of the boundary layer: Integration of measurements and methods. J. Atmos. Oceanic Technol., 25, 1251-1266.

Luo, Y., K. M. Xu, H. Morrison, and G. McFarquhar, 2008: Arctic mixed-phase clouds simulated by a cloud-resolving model: Comparison with ARM observations and sensitivity to microphysics parameterizations. J. Atmos. Sci., 65, 1285-1303.

Matrosov, S. Y., 2007: Modeling backscatter properties of snowfall at millimeter wavelengths. J. Atmos. Sci., 64, 1727-1736.

— , R. F. Reinking, and I. V. Djalalova, 2005: Inferring fall attitudes of pristine dendritic crystals from polarimetric radar data. J. Atmos. Sci., 62, 241-250.

Mätzler, C., and J. Morland, 2009: Refined physical retrieval of integrated water vapor and cloud liquid 
for microwave radiometer data. IEEE Trans. Geosci. Remote Sens., 47, 1585-1594.

Melchionna, S., M. Bauer, and G. Peters, 2008: A new algorithm for the extraction of cloud parameters using multipeak analysis of cloud radar data-First application and preliminary results. Meteor. Z., 17, 613-620.

Muramoto, K.-I., K. Matsuura, and T. Shiina, 1995: Measuring the density of snow particles and snowfall rate. Electron. Commun. Japan, 78, 71-79. doi:10.1002/ecjc.4430781107.

Nešpor, V., W. F. Krajewski, and A. Kruger, 2000: Windinduced error of raindrop size distribution measurement using a two-dimensional video disdrometer. J. Atmos. Oceanic Technol., 17, 1483-1492.

Noh, Y.-J., G. Liu, E.-K. Seo, J. R. Wang, and K. Aonashi, 2006: Development of a snowfall retrieval algorithm at high microwave frequencies. J. Geophys. Res., 111, D22216, doi:10.1029/2005JD006826.

$\longrightarrow,-$, A. S. Jones, and T. H. Vonder Haar, 2009: Toward snowfall retrieval over land by combining satellite and in situ measurements. J. Geophys. Res., 114, D24205, doi:10.1029/2009JD012307.

Peters, G., B. Fischer, and T. Andersson, 2002: Rain observations with a vertically looking micro rain radar (MRR). Boreal Environ. Res., 7, 353-362.

Petty, G. W., and W. Huang, 2010: Microwave backscatter and extinction by soft ice spheres and complex snow aggregates. J. Atmos. Sci., 67, 769-787.

Rose, T., S. Crewell, U. Löhnert, and C. Simmer, 2005: A network suitable microwave radiometer for operational monitoring of the cloudy atmo- sphere. Atmos. Res., 75, 183-200, doi:10.1016/j. atmosres.2004.12.005.

Rosenberg, R., 2005: Why is ice slippery? Phys. Today, 58, 50-55.

Seifert, A., and K. D. Beheng, 2006: A two-moment cloud microphysics parameterization for mixed phase clouds. Part 1: Model description. Meteor. Atmos. Phys., 92, 45-66.

Sevruk, B., M. Ondrás, and B. Chvíla, 2009: The WMO precipitation measurement intercomparisons. Atmos. Res., 92, 376-380, doi:10.1016/j. atmosres.2009.01.016.

Solomon, A., H. Morrison, O. Persson, M. D. Shupe, and J. W. Bao, 2009: Investigation of microphysical parameterizations of snow and ice in arctic clouds during M-PACE through model-observation comparisons. Mon. Wea. Rev., 137, 3110-3128.

Stephens, G. L., and Coauthors, 2002: The CloudSat mission and the A-Train. Bull. Amer. Meteor. Soc., 83, 1771-1790.

Tanelli, S., S. L. Durden, E. Im, G. M. Heymsfield, P. Racette, and D. O. Starr, 2009: Next-generation spaceborne cloud profiling radars. Proc. IEEE Radar Conf., Pasadena, CA, IEEE, 1-6.

Verlinde, J., and Coauthors, 2007: The Mixed-Phase Arctic Cloud Experiment. Bull. Amer. Meteor. Soc., 88, 205-221.

Weng, F., L. Zhao, R. R. Ferraro, G. Poe, X. Li, and N. C. Grody, 2003: Advanced microwave sounding unit cloud and precipitation algorithms. Radio Sci., 38, 8068, doi:10.1029/2002RS002679. 